\title{
The Development and Teaching Characteristics of Chinese bel canto
}

\author{
Chunhua Chen ${ }^{1, \text { a }}$ \\ ${ }^{1}$ Shaanxi Xueqian Normal University, Xi'an, Shaanxi Province, China \\ a2481533218@qq.com
}

Keywords: Bel canto, Bel canto teaching, Bel canto development, Bel canto teaching characteristics

\begin{abstract}
Bel canto in today's can be said is the world's high level of singing arts representatives and symbols. At present, the rapid development of science and technology, the vocal music art genre into the forms and performing techniques have greatly improvement, more and more people accept and appreciate bel canto. The bel canto of the spread and development in China in the history and the development trend of bel canto in China are reviewed, the road of development in China is explored in this paper. It is a practical significance and long-term significance of academic issues.
\end{abstract}

\section{Introduction}

Bel canto originated from Italy, from the birth of western religious music in the background, from the earliest "eunuch singers". "Eunuch singers" has created a set of singing method be preserved, the improvement and carry forward, gradually become a special sound method of the classical Italian style form and sound. Bel canto, after the formation of gradually extended to other European countries [1]. At the beginning of the 20th century, was introduced into China.

Bel canto of the main characteristics of different from other styles, summed up in one sentence is the bel canto is mixed acoustic area etc [1]. Bel canto voice from speaking, is the true sound of falsetto in, sound is true or false according to the needs of the pitch ratio mixed with use. From resonance for, is to sing the resonance cavity can all mobilize. This kind of style itself has his own special "taste", characteristic of the acoustic characteristics [1]. Learn and master the process of bel canto, equal with our singing training to make our voice and instrument. Needed to bel canto singing instrument sing song has his unique "taste".

\section{The development of bel canto in China}

The development of Chinese opera art in the 20th century, from its history through the look, can be roughly divided into four periods: the 20-40 s initial, development of 50-60 - s, stagnation in the "cultural revolution" era, the era of reform and opening up the boom in an all-round way. This is the bel canto in China from exploring a tortuous process of gradually mature [1].

Early-stage bel canto, the then Chinese vocal music art, is stands out as the main characteristics of the bel canto [2]. Vocal music works are mostly art song and song depicting the awakening of public saving is given priority to, from the perspective of a movie sound material, can feel at that time, the characteristics of the bel canto voice more natural, because at the beginning of bel canto in abroad, for national folk singing at that time almost no too big effect.

After the founding, with the growth of the professional colleges and universities teachers, bel canto to enter into the development period, this period, due to the ideas of the "left" impression, walking on the bel canto to explore some detours, due to the great differences in the understanding of bel canto, articulation appeared before and after the conflict, influence the bel canto development progress in China, but this time bel canto of the fusion of Chinese folk have a preliminary attempt, opera "sister jiang" is the bel canto and folk singing a success story from each other [2]. Throughout the development of Chinese vocal music art, both in time and space, great changes have taken place. Advance of the art of bel canto in China twists and turns. 
"Comrade" started in 1977, the Chinese opera art ushered in the new of one page, especially since the reform and opening, the development of more opened her spring. Reform and opening up has brought the diversity of music creation, at the same time, also bel canto boom of development by leaps and bounds [3]. With the least amount of effort to exert the largest energy of bel canto voice scientific vocalization methods, got more recognition field [3]. Bel canto emerged a large number of talented young singers, some of the outstanding figures in the international vocal competition to obtain high, because the attention of the international, they by Oriental unique temperament and national verve shocked the world, won the honor for China's vocal music art. Is no doubt that for the Chinese opera art played their part?

\section{The teaching characteristics of bel canto}

In the process of vocal music teaching, don't too much to tell the students at the beginning of the training of vocal music theory, so it is easy to put their ideology mess, will give students the way to solve the problem., for example, some classmates in vocal music training can your tongue, tongue stiff problems, in this case, cannot simply tell students, theoretical flat to the back of your tongue, too, to relax the tongue, and let the mouth in a relaxed state, so can make the students can't good understanding so relatively abstract concept, don't know how to relax, nor is it clear to overwork your mouth state how, as a vocal music teacher can use the "li", "la", such as the sound source, let the students' attention to the tip of the tongue, to relax the tongue, such specific training methods to solve practical problems [3]. When students have to sing to tell him in our method, let he clearly know how to do is right, that he sang in the theoretical knowledge and practice has a clear concept, and this kind of concept to consolidate, so there will be a correct sound feeling. So the foundation, to master the basic skills is very important.

The wider the range of a unified teaching. Bel canto singer can sing to two octaves, especially in coloratura soprano and some of the singers can sing to two and a half octave, even can achieve three octaves [3]. So will be included in a wide range of three different vocal register, the acoustic area because of human's natural voice and present a different tone, but bel canto make it a smooth transition, and achieve the perfect unity.

To development of the bel canto art with Chinese characteristics, we need to have their own unique things. Bel canto development of today's professional music college vocal music teaching and puts forward the new challenge, and develop vocal music talents, for instance, is known as the "Chinese and western nightingale" has done it in bel canto, folk two styles have got the gold medal [3]. Bel canto and other singing voice will promote more scientific, break the pattern of collection, formed a variety of style at the same time.

In the development of the bel canto at the same time, we can clearly see the bel canto voice of science principle more recognition and reference [3]. Of ancient qin opera, for example, due to the specific natural environment on the loess plateau, form a unique plateau singing, due to the change of The Times, "qin and aesthetic temperament and interest in today's youth have a certain distance, in order to make the ancient qin opera can be accepted by more people, from many aspects, singing, band, music has carried on the reform, especially the" qin industry many actors began to notice the bel canto in the open, relax throat singing technique is applied, which can overcome the crowded, with sound habits, make this style is accepted by the modern people [4].

Chest type joint teaching breathing. Bel canto school singing breath is to adopt joint breathing, chest type is both singing and singing opera in the world using the breath is one of the most scientific breathing method. This breathing elastic can control, strong scalability, breath storage; If the vocal cords and cooperate with the clever is not only the volume but can small, can be high to low; And have a good voice coherence and bounce [4]. At the same time, the scientific use of the vibration frequency of the vocal cords. With awareness and phonetic change and the adjustment of the pharyngeal tubular, favorable control the vibration of the vocal cords frequency function, and give full play to the vocal cords beautiful timbre and sound quality fluctuation.

In bel canto in the process of teaching, the teacher often emphasizes the respiratory support, that what is called a "breathing support", how to do? Man is the inspiratory muscle groups and exhale 
breath muscles to drive, inspiratory muscle groups including down from a chest, mainly is the underside, around the waist and back [4]. Another is expiratory muscles, "in life!" "Alas!" Cough, sneeze is expiratory muscles work. This group of muscles is very strong, but don't need to be very strong in singing. When we are singing, is the need to nose and mouth with suck, quickly absorb deep, this is a kind of feeling, each person's experience may differ, in vocal music teaching, we often put it compared to "yawn" and "smell the flowers", etc. Sucked into the air, inspiratory muscles will continue to work, can not relax, that remains on the inhale, and makes the breath to become a kind of confrontation, this fight is we often say that the support of the "breathing" [4]. Shout against smoking inside the body to produce a pressure, suction inlet constantly expand the lower part of the lung, the expansion around the waist muscle outward expansion, the body is caused by the diaphragm down. So, in the vocal music training, while the students are singing breath against relaxation is inspiratory muscle force, the teacher will prompt students to "sing", to keep a good state of suction, suction cavity is opened, so also has a rich, will naturally make the right sound.

True and false of sound mixing teaching methods. When we are in the difference between bel canto and other singing, "zone mixed chorus singing" is the most important characteristics of bel canto.

In bel canto voice, the sound is true or false according to certain proportion of pitch mix use, on the basis of the real sound, with the rise of the pitch, false acoustic components increase gradually and become false sound is given priority to, that is true or false is used, that is absolutely true and false sound mixing, not just the mixture of voice and also mixed resonance state, resulting in a completely unified phenomenon [4]. So in bel canto singing training, we will emphasize the proportion of true and false voice in what state, to mix to what extent, sound sound as true or false.

Need to play music instrument, any a kind of Musical Instruments need to have a design, drawing, material, production process, but vocal music "instruments" are long on themselves, this instrument is to through the correct scientific singing training to produce it, and good singing method is the process of making Musical Instruments [3]. Through scientific singing training to produce vocal Musical Instruments are needed to sing pitch, range, and to sing beautiful moving, express love music, and singer does not feel tired, sore throat. Method has a good singing, singing makes can freely (SMS), and can prolong the life of art, it is the teachers and students work together in the vocal music teaching goal.

The use of the echo chamber in teaching. Say from resonance, bel canto is full, is mixed vocal register, mixed echo, sound true and false hybrid resonate at the same time, we are singing at the same time, the full use of the human body the chest cavity resonance, laryngeal pharynx cavity resonance, oropharyngeal cavity resonance, nasopharyngeal cavity resonance, oral resonance, the nasal resonance cavity resonance as the head, to actively mobilize, make its "lasting appeal is dye-in-the-wood", achieve unique sound effects [5].

Because everyone's vocal organs on the physiological structure of the basic same, but each have differences, so in singing training, "one thousand" teaching mode is not desirable [5]. Vocal music teachers will be according to the actual conditions of voice of students, and nurture long-term life habits, hobbies, accept ability, the influence factors, such as research objective, realistic analysis, adopt consistent with scientific commonness and training methods in accordance with individual voice characteristics, undertake to the student scientific and effective training in singing.

The unique teaching characteristics. Articulation of bel canto is on the jaws and the corners of the mouth, not in the form; and the change of vowel is on the vocal cords, formed in the pharynx, and namely is to sing "rhyme" [6]. This kind of pronunciation method more round, which helps breathe with the vocal cords, penetrating voice, beautiful mouth freely.

As the basic theory of vocal music teachers need to have a solid foundation and rich practical experience, but also the theory and in practice experience and empirical experience to sum up to summarize and extract, flexible used in vocal music teaching. In vocal music teaching work, very rich practical experience of the teacher will be very consciously guides the student embarks from the music, sing very natural, pleasant voice [6]. The most important question is: we are in the process of vocal music teaching training standards is what? This standard is the voice of right concept, it is our 
ears. Good sound concept is very important, vocal music teacher's ultimate purpose is to change students' concept of sound, and the process of vocal music teaching is actually a process of constant change student's sound concept, training teachers and students of the ear. Vocal music teachers must be a able to correctly judge the students sound good or bad or not ears, without a good hearing is impossible in the various problems in vocal music training for students to make the right judgment, no good, targeted solution to the problem.

Progressive characteristics of teaching. As a vocal music teacher, is auditory training is especially important, because you are not to judge a person, you want to hand in a number of students at the same time, while the teaching principle is the same, but specific to each student body, there is not the same, and sometimes it will be very different, and as a vocal music teacher, must not to own a certain experience, a phenomenon as a substitute for the status of the students differ in thousands ways [7]. That is to say, when to teach a student, is not the experience of using copy to another student, need specific issues specific analysis. We all know the problem seems to be, but in the practical training is the most error-prone. So in vocal music training must follow certain principles: to see and hear students singing respiration is used properly; Voice with is correct; The voice of right or wrong; Language is "clear pronunciation and mellow voice"; The effect of resonance is rich; When dealing with specific works, to express the song with the voice of what kind of feelings, want to use what kind of efforts to handle songs, each vocal music teachers should put themselves in standing in the position of each student body they want to, he is the best voice and state what kind of, to a certain degree of students will be given his plasticity problem, every one of us is not only sing a sound, so the teacher will be good at discovering plasticity, students performance ability and ability of the performance will make him get development [7].

\section{Conclusion}

Said on put together is narrated, bel canto as a skill very arts and sciences, it has a broad, smooth breath voice coherent, mixed chorus music singing, make full use of resonance cavity body, unique characteristics such as teaching. In the process of bel canto vocal music teaching, not only need to follow the rules of singing art, also need to vocal music between teachers and students actively cooperate with, causes the student to maximize the understanding and mastering the basic elements of the bel canto vocal music training.

\section{Acknowledgement}

This project, Research on the Development and Operation Mode of Art Music Theatre and Its Value in Shaanxi's Cultural Industry Chain, is supported by Social Science Funding of Shaanxi Province in 2015 (Projcet No.:2015J023).

\section{References}

[1] H.H. Liang and T.Y. Xu, The origin of the Italian bel canto, Shanghai music college press, 2010, pp.11-18.

[2] K.Y. Li, Bel canto method of teaching, Journal of music education, 2009, pp.43-48.

[3] Sh.T. Zhong and B. Wu, Vocal music teaching, The Hebei education publishing house, 2004, pp.62-67

[4] D.P. Teng, The current situation of the development of Chinese opera, people's music, 2011, pp.35-39

[5] Jie. Li and W. Xiong, Teaching Chinese bel canto, Journal of music education, 2001, pp.63-67

[6] X.G. Huang, Vocal music teaching in folk singing and bel canto, people's music, 2008, pp.17-23. 
[7] J. Zh. Liu and G.Y. Liang, The difference between bel canto and folk singing, Journal of music education, 2013, pp.11-16. 